\title{
Program for APOE-E4 allele detection in a Mexican population of older patients with cognitive impairment
}

\author{
Alma Delia Genis-Mendoza, ${ }^{1}$ José Jaime Martínez-Magaña, ${ }^{1}$ Carolina Bojórquez, ${ }^{1}$ \\ José Alberto Téllez-Martínez, ${ }^{1}$ Janett Jiménez-Genchi, ${ }^{2}$ Andrés Roche, ${ }^{2}$ Alexis Bojorge, ${ }^{2}$ Mariana Chávez, ${ }^{2}$ \\ Carlos Castañeda, ${ }^{2}$ Rafael Guzmán, ${ }^{3}$ Leonor Zapata, ${ }^{3}$ Dione Aguilar-Méndez, ${ }^{3}$ Nuria Lanzagorta, ${ }^{4}$ \\ Ileana Rebolledo, ${ }^{4}$ Susana Castro-Chavira, ${ }^{5}$ Thalía Fernández, ${ }^{5}$ Lorena Orozco, ${ }^{6}$ Humberto Nicolini and \\ Angélica Graciela Martínez-Hernández ${ }^{6}$ \\ 'Secretaría de Salud, Instituto Nacional de Medicina Genómica, Laboratory of Psychiatric and Neurodegenerative Diseases Genomics, Ciudad de \\ México, Mexico; ${ }^{2}$ Secretaría de Salud, Hospital "Fray Bernardino Álvarez", Psychiatric Care Departments, Ciudad de México, Mexico; ${ }^{3}$ Secretaría \\ de Salud, Hospital General de México, Geriatrics Clinic, Ciudad de México, Mexico; ${ }^{4}$ Grupo Médico Carracci, Ciudad de México, Mexico; \\ ${ }^{5}$ Universidad Nacional Autónoma de México, Institute of Neurology, Querétaro, Mexico; ${ }^{6}$ Secretaría de Salud, Instituto Nacional de Medicina \\ Genómica, Laboratory of Immunogenomics and Metabolic Diseases, Ciudad de México, Mexico
}

\begin{abstract}
Introduction: In Mexico, the prevalence of neurocognitive disorders (NCDs) has increased in parallel with the increase in life expectancy. The $E 4$ allele of the gene that encodes apolipoprotein $E(A P O E)$ is the main genetic risk factor for cognitive impairment. Objective: To replicate the association of APOE-E4 allele with neurocognitive impairment in a Mexican population, as well as to implement a genetic risk-detection program with the APOE-E4 allele. Method: A program was structured for the detection of APOE-E4 allele risk in different recruiting centers from the central zone of the Mexican Republic, with three stages: recruitment and selection of candidates for the detection of the risk-allele, genetic risk analysis and delivery of results. Results: In the genetic-association study to replicate the association with neurocognitive disorders by means of multivariate logistic models, the APOE-E4 allele increased the risk for cognitive impairment in the Mexican populations by approximately $6 \%$ (OR: 5.83, $p=0.0025)$. In addition, 367 genetic risk results were delivered. Conclusions: The present program is the first one to be implemented in Mexico with the purpose to inform on a genetic risk factor for neurocognitive disorders in several centers of the country.
\end{abstract}

KEY WORDS: Neurocognitive disorders. Genetic markers. Cognitive impairment.

\section{Introduction}

The World Health Organization estimates that approximately 35.6 million people in the world have been diagnosed with some type of neurocognitive disorder (NCD), and this number is expected double every 20 years. In Mexico, the National Study on Health and Aging in Mexico (Enasem - Estudio Nacional sobre Salud y Envejecimiento) reported that $7 \%$ of the Mexican population suffered some type of minor NCD (previously called mild cognitive impairment) and $3 \%$ had clinical data consistent with major NCD (dementia). ${ }^{1-3}$
According to the Diagnostic and Statistical Manual of Mental Disorders fifth edition (DSM-5), NCDs can be divided in major and minor disorders according to the level of functional capacity preservation or compromise; cognitive impairment should not be present since birth or early in life, and should involve at least two or more cognitive domains (attention, executive, learning and memory functions, language, visual perceptual skills, social cognition).

Based on these criteria, said manual recognizes the following NCDs: Alzheimer's disease (AD)-associated, frontotemporal, Lewy body, vascular, traumatic brain injury-associated, human immunodeficiency virus infection,
Correspondence: Humberto Nicolini

E-mail: hnicolini@ inmegen.gob.mx
Date of reception: 12-10-2017

Date of acceptance: 23-04-2018

DOI://dx.doi.org/10.24875/GMM.M18000189
Gac Med Mex. 2018;154:470-474

Contents available at PubMed www.gacetamedicademexico.com 
Huntington's disease, Parkinson's disease, prion disease, or substance-induced, of multiple etiology, as well as unspecified NCDs (American Psychiatric Association 2013). Of all of the above, AD-associated NCD is the most highly prevalent.

The economic impact that NCDs represent in the world amounts to about 604 billion dollars, almost half of Mexico's gross domestic product. ${ }^{4}$ For this reason and due the alarming increase in their prevalence, NCDs mainly by AD represent a public health problem in the world and Mexico.

Even when $A D$ etiology has not been clearly established, several factors have been identified to increase the risk for its appearance: physical inactivity, smoking, high blood pressure, obesity, diabetes, depression, low educational level and some mutations at the genetic level. ${ }^{5}$ Clinical investigations, mainly in high-income countries such as the United States and the United Kingdom, have suggested that fighting these risk factors and early diagnosing individuals at high risk would have a positive impact on the reduction of the prevalence of suffering from AD-type NCD. ${ }^{6,7}$

The purpose of generating a set of tools that allow to group individuals with high risk for developing $A D$ has been the point of convergence of recent investigations. In this sense, various clinical and cognitive evaluations have been developed, as well as cerebrospinal fluid markers, at the neuroimaging and genetic level. ${ }^{8}$ However, as it occurs in other diseases, some have been reconsidered due to their high cost, in addition to that most are observable when the disease is at advanced stages. ${ }^{9}$

Genetic markers have shown good predictive values for Alzheimer's disease, mainly apolipoprotein E (APOE) E4 allele. ${ }^{10}$ Being a carrier of an APOE E4 allele copy is known to increase 3 times the risk of $A D$; while being a carrier of two allele copies can increase it up to 15fold. ${ }^{11,12}$ The association between the APOE-E4 gene and Alzheimer's disease has been replicated so many times that the United States Food and Drug Administration approved its use as a genetic risk marker for this NCD (https://www.fda.gov/newsevents/newsroom/ pressannouncements/ucm551185.htm).

However, in Mexico and in numerous middle and low economic income countries, genetic screening programs that allow to detect individuals at high risk for suffering AD or some other type of NCD have not yet been established. In 2015, Gutiérrez Robledo et al. noted that in Mexico it was urgent to generate programs that would allow individuals with high risk of dementia to be identified in order to establish intervention strategies in this population. ${ }^{13}$ Taking this premise as a basis, we present a collaborative program between different Mexican institutions for the detection of individuals at high genetic risk for NCD, which we have named "Te APOyo" (I support you).

\section{Method}

The APOE-E4 detection "Te APOyo" program was structured in three stages.

\section{Recruitment and selection of candidates for risk allele detection}

Patients were evaluated by psychiatrists, psychologists or geriatricians with training in NCD. The clinical staff decided if the patient was candidate to continue with risk allele evaluation. Inclusion criteria were being older than 60 years, having a cognitive function impairment baseline self-report, as shown by subjective complaint of memory loss of or deterioration of some other cognitive domain such as attention, executive functions, language, visual constructional abilities, visual perceptual skills, social cognition or clinimetry consistent with cognitive impairment $(<24$ points in the Mini-Mental State Examination test). ${ }^{14,15}$

Subjects were excluded from the study if they had conditions that did not allow proper clinical or clinimetric evaluation: acute psychiatric symptomatology (psychotic, anxious or affective), intoxication or dependence on substances or drugs, intellectual disability, acute brain damage, among others. All participants were asked to put their consent to participate in the investigation in writing, after information and clarification of doubts.

\section{Genotype analysis}

After clinical assessment, biological samples were obtained from the subjects, such as peripheral blood or epithelial cells scraping from inside the cheeks. The requested biological samples were used to extract DNA, which was obtained with a modified salting-out commercial method (Gentra Puregene ${ }^{\circledR}$, Qiagen), with the protocol being adjusted according to the manufacturer specifications to process the samples.

APOE gene polymorphisms (rs7412 and rs429358) genotyping was performed by means of real-time polymerase chain reaction assays, using Taqman ${ }^{\circledR}$ probes (Applied Biosystems, San Francisco, CA, USA). For the rs429358 and rs7412 polymorphisms genotyping, the C_3084793_20 and C_904973_10 assays, respectively, were used. Thermocycling conditions were those established by the supplier for each assay. Thermocycling and allelic discrimination were performed on the real-time equipment Quant 


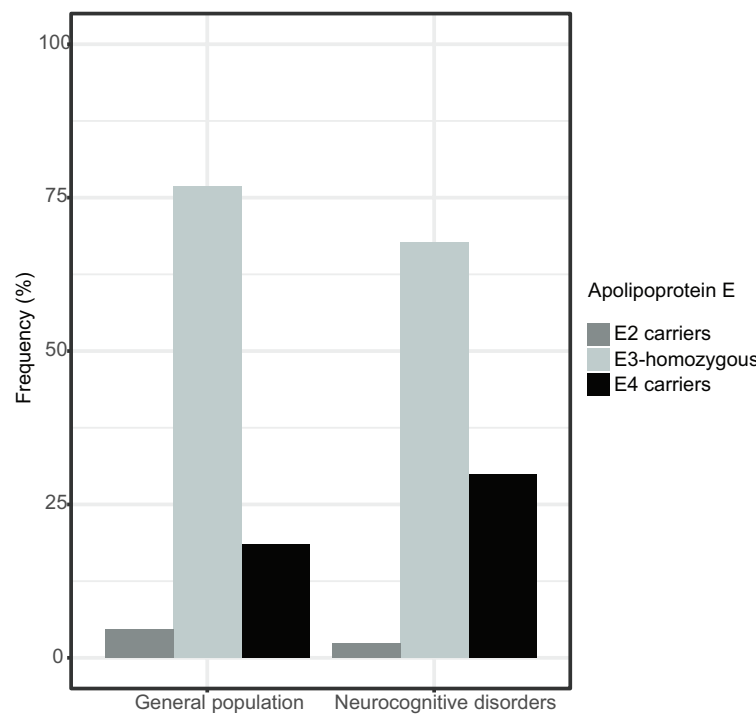

Figure 1. APOE distribution in a Mexican population. The group of individuals with cognitive impairment shows an increase in the frequency of allele E4.

Studio 6 Flex $^{\circledast}$ (Applied Biosystems, San Francisco, CA, USA.

Once the genetic risk results were generated, they were reported to each patient and his/her primary caregiver, using a format designed for easy understanding of the information (Appendix 1).

\section{Delivery of results}

Approximately one month after the biological sample was taken, the genetic risk result was generated. The treating physician and a psychologist trained in the management of patients with NCD delivered the results personally to each participant in presence of a family member or companion, using a format designed for the protocol and for each one of the recruitment centers (Appendix 1).

\section{Statistical analysis}

With the purpose to replicate the association of $A P O E$ with NCD, multivariate logistic models, adjusted for age and gender were implemented. The analyses were performed comparing the allelic frequencies of $A P O E-E 3$ with those of $A P O E-E 4$.

\section{Results}

The genetic association analysis replicated the allele APOE-E4 association with NCD in the Mexican population. From the general population, 1307 Mexican mestizo individuals were previously recruited, who were regarded as
Table 1. Comparison of $A P O E$ frequencies in a Mexican population

\begin{tabular}{|c|c|c|c|c|}
\hline & \multicolumn{2}{|c|}{ General population $(n=1307)$} & \multicolumn{2}{|c|}{$\operatorname{NCD}(n=297)$} \\
\hline & $\mathrm{n}$ & $\%$ & $\mathrm{n}$ & $\%$ \\
\hline \multicolumn{5}{|c|}{ APOE genotypes } \\
\hline E2/E2 & 2 & 0.15 & 0 & 0.00 \\
\hline E2/E3 & 57 & 4.36 & 7 & 2.36 \\
\hline E2/E4 & 2 & 0.1 & 0 & 0.00 \\
\hline E3/E3 & 1005 & 76.89 & 201 & 67.68 \\
\hline $\mathrm{E} 3 / \mathrm{E}^{*}$ & 218 & 16.68 & 76 & 25.59 \\
\hline $\mathrm{E} 4 / \mathrm{E}^{*}$ & 23 & 1.76 & 13 & 4.38 \\
\hline \multicolumn{4}{|c|}{ APOE alleles } & \\
\hline E2 & & 2.41 & & $=1.18$ \\
\hline E3 & & 87.41 & & 81.64 \\
\hline E4 & & 10.10 & & 97.17 \\
\hline
\end{tabular}

${ }^{*}$ Risk genotypes, $\mathrm{NCD}=$ major neurocognitive disorder, $\mathrm{APOE}=$ gene that encodes apolipoprotein $\mathrm{E}$.

Participants with homozygous genotype for APOE-E4 exhibited a risk factor for NCD approximately 6-fold higher (odds ratio, $\mathrm{OR}=5.83,[2.23-14.78]$ and $p=0.0025$ ); in those who were heterozygous for $E 4$ allele, the risk was approximately twice as high (OR $=1.78,[1.14-2.76]$ and $p=0.0104)$. Table 1 and Figure 1 summarize the allelic and genotypic frequencies of the analyzed population.

So far, 297 subjects older than 60 years and 70 first-degree relatives of subjects with NCD have been genetically evaluated. The centers where the program has been implemented are Hospital Psiquiátrico "Fray Bernardino Álvarez", the Neurology Institute in Querétaro (National Autonomous University of Mexico), Hospital General de Mexico and Grupo Médico Carracci.

\section{Discussion}

Identification of individuals with high genetic risk for some disease prior to the manifestation of symptoms might help to decrease prevalence rates. ${ }^{17}$ For the first time, we have implemented in Mexico a screening program to detect individuals with high genetic risk for NCD based on the APOE gene isoforms.

Additionally, with the purpose to identify a risk factor of the APOE isoforms with NCD in the Mexican population, an association study of APOE-E4 with NCD was performed in this population, since it has been one of the most constant relationships and has been more often replicated in different human groups around the world, ${ }^{18-20}$ though not in the Mexican population..$^{1}$

Just as it occurs in other populations, we identified that in the Mexican population the APOE-E4 allele increased the risk for TNC, which opens the door to propose new therapeutic strategies using drugs that employ $A P O E$ isoforms-related molecular targets. ${ }^{22}$ 
In recent years, as previously noted, the idea of using markers has increased in the clinical area to aid the diagnosis and early therapeutic intervention. One characteristic of genetic tests in comparison with other methods for the assessment of individuals with high risk for NCD, such as functional magnetic resonance, is its low cost. However, there has been discussion on whether in low-resource and developing countries, such as Mexico, is it feasible to implement them in clinical care and whether they can be accessible to the entire population. ${ }^{23}$

In this sense, we decided to implement this program to try to directly impact on the clinical area and narrow the gap between genetic data and their clinical implementation, involving physicians, psychologists and support staff that regularly looks after the patient. Unfortunately, even when the program is operating in four different centers of the country, further efforts are required in order for it to be able impact on other places and be economically accessible to the entire population at risk, since the higher the demand, the lower the costs.

\section{Conclusions}

"Te APOyo" is the first program in Mexico for detection of the genetic risk conferred by being a carrier of the APOE-E4 allele for the development of neurocognitive disorder. In the genetic association analysis with the general population, previous analyses where the $A P O E-E 4$ allele was estimated to be a risk factor for $N C D$ in the allele-carrier population were replicated.

It is expected that when program participants who are carriers of the risk allele become aware of it, will change their lifestyle in terms of nutrition, sleep hygiene and physical activity, among other aspects, as it has been documented in other countries, and that even show themselves optimistic with the results of the test; ${ }^{24}$ However, it will be necessary to follow up on our population to know their behavior.

Either way, further basic research is required in order to discover other genetic variants that might be implemented in the clinical area as NCD risk markers, in addition to APOE-E4.

\section{Acknowledgements}

To Alejandro Velázquez and Erick Alejandro Izquierdo García, for their help and enthusiasm during the performance of this project.

\section{References}

1. Llibre-Rodríguez JJ, Ferri CP, Acosta D, Guerra M, Huang Y, Jacob KS, et. al. Prevalence of dementia in Latin America, India, and China: a population-based cross-sectional survey. Lancet. 2008;372(9637): 464-474.

2. Prince M, Bryce R, Albanese E, Wimo A, Ribeiro W, Ferri CP. The global prevalence of dementia: a systematic review and metaanalysis. Alzheimers Dement. 2013;9(1):63-75.

3. Mejía-Arango S, Gutiérrez LM. Prevalence and incidence rates of dementia and cognitive impairment no dementia in the Mexican population: data from the Mexican Health and Aging Study. J Aging Health. 2011; 23(7):1050-1074.

4. Stefanacci RG. The costs of Alzheimer's disease and the value of effective therapies. Am J Manag Care. 2011;17(Suppl13):S356-S362.

5. The Lancet Neurology. Pointing the way to primary prevention of dementia. Lancet Neurol. 2017;16(9):677.

6. Daviglus ML, Bell CC, Berrettini W, Bowen PE, Connolly ES, Cox NJ, et al. NIH state-of-the-science conference statement: preventing Alzheimer's disease and cognitive decline. NIH Consens State Sci Statements. 2010;27(4):1-30.

7. Barnett JH, Lewis L, Blackwell AD, Taylor M. Early intervention in Alzheimer's disease: a health economic study of the effects of diagnostic timing. BMC Neurol. 2014;14:101.

8. Panegyres PK, Berry R, Burchell J. Early Dementia Screening.Diagnostics. 2016;6(1):6.

9. Hampel H, Broich K, Hoessler Y, Pantel J. Biological markers for early detection and pharmacological treatment of Alzheimer's disease. Dialogues Clin Neurosci. 2009;11(2):141-157.

10. Elias-Sonnenschein LS, Viechtbauer W, Ramakers IH, Verhey FR, Visser PJ. Predictive value of APOE- $\varepsilon 4$ allele for progression from $\mathrm{MCl}$ to AD-type dementia: a meta-analysis. J Neurol Neurosurg Psychiatry. 2011;82(10):1149-1156.

11. Bertram L, McQueen MB, Mullin K, Blacker D, Tanzi RE. Systematic meta-analyses of Alzheimer disease genetic association studies: the AlzGene database. Nat Genet. 2007;39(1):17-23.

12. Qian J, Wolters FJ, Beiser A, Haan M, Ikram MA, Karlawish J, et al. APOE-related risk of mild cognitive impairment and dementia for prevention trials: an analysis of four cohorts. PLoS Med. 2017;14(3):e1002254.

13. Gutiérrez-Robledo LM, Arrieta-Cruz I. Dementia in Mexico: the need for a National Alzheimer's Plan. Gac Med Mex. 2015;151(5):667-673.

14. Diagnostic and statistical manual of mental disorders. Quinta edición. EE.UU.: American Psychiatric Association; 2013.

15. Folstein MF, Folstein SE, McHugh PR. "Mini-mental state". A practical method for grading the cognitive state of patients for the clinician. J Psychiatr Res. 1975;12(3):189-198.

16. Contreras-Cubas $C$, Sánchez-Hernández B, García-Ortiz H, Martínez-Hernán$\operatorname{dez}$ A, Barajas-Olmos F, Cid M, et. al. Heterogenous distribution of MTHFR gene variants among mestizos and diverse Amerindian groups from Mexico. PLoS One. 2016;11(9):e0163248.

17. Andermann A, Blancquaert I. Genetic screening: a primer for primary care. Can Fam Physician. 2010;56(4):333-339.

18. Ihle $A$, Bunce $D$, Kliegel M. APOE $\varepsilon 4$ and cognitive function in early life: a meta-analysis. Neuropsychology. 2012;26(3):267-277.

19. Agarwal R, Tripathi CB. Association of apolipoprotein E genetic variation in Alzheimer's disease in Indian population: a meta-analysis. Am J Alzheimers Dis Other Demen. 2014;29(7):575-582.

20. Chen K, Sun YM, Zhou Y, Zhao Q, Ding D, Guo Q. Associations between APOE polymorphisms and seven diseases with cognitive impairment including Alzheimer's disease, frontotemporal dementia, and dementia with Lewy bodies in southeast China. Psychiatr Genet. 2016; 26(3):124-131.

21. Campos M, Edland SD, Peavy GM. An exploratory study of APOE- $\varepsilon 4$ genotype and risk of Alzheimer's disease in Mexican Hispanics. J Am Geriatr Soc. 2013;61(6):1038-1040.

22. Yamazaki Y, Painter MM, Bu G, Kanekiyo T. Apolipoprotein E as a therapeutic target in Alzheimer's disease: a review of basic research and clinical evidence. CNS Drugs. 2016;30(9):773-789.

23. Maltese PE, Poplavskaia E, Malyutkina I, Sirocco F, Bonizzato A, Capodicasa N, et. al. Genetic tests for low- and middle-income countries: a literature review. Genet Mol Res. 2017;16(1).

24. Ashida S, Koehly LM, Roberts JS, Chen CA, Hiraki S, Green RC. Disclosing the disclosure: factors associated with communicating the results of genetic susceptibility testing for Alzheimer's disease. J Health Commun. 2009;76814(8):768-784 
Gaceta Médica de México. 2018;154

\section{Appendix 1. Results delivery form}

What are genes?

A gene contains genetically inherited information.

Each person has two copies of each gene, one comes from his/ her mother and another from his/ her father.

Families share genes, customs, diet and an environment.

Diseases are the result of inheritance, genetics, lifestyle and environment of each person.

It is possible for people with similar genes to contract a disease or not.

This depends on lifestyle and environment.

Genes CANNOT be changed, but lifestyle CAN be controlled or changed.

Having the risk gene does NOT mean that you will develop the disease.

How do my genes influence on the development of a disease?

How genetically similar are you with your family? -You share $50 \%$ of your genetic information with your parents, children and siblings (first-degree relatives), while with your grandparents, aunts and uncles and half-brothers (second degree), you only share $25 \%$.

How does the risk for developing a disease vary according to your family history?

\section{-Low}

-One relative (second degree) in both branches.

-You do not know your family history or you are adopted.

\section{-Moderate}

-One relative ( $1^{\text {st }}$ degree) with unknown or late-onset symptoms.

-2 relatives ( $2^{\text {nd }}$ degree) in the same branch with of late-onset or unknown symptoms.

-High

-Two or more relatives ( $1^{\text {st }}$ or $2^{\text {nd }}$ degree) in one or both branches, with early, late or unknown-onset symptoms.

\section{How do my genes influence?}

-All people have the same genes. However, these can occur in slightly different forms (alleles).

-The susceptibility allele mostly associated with dementia is the APOE4 gene.

What other factors are taken into account to calculate risk?

-Age of relative at diagnosis

-Personal clinical history

-Environmental factors

-Social factors
What is dementia?

-It implies certain loss of brain normal function.

-It usually affects judgment, behavior, language, memory and thinking. -To establish a diagnosis, a psychiatric, neurological or neurophysiological assessment should be carried out.

What is Alzheimer's disease?

-It is the most common type of disease that affects memory loss.

-At older age, the risk for suffering from it increases.

- It can be of late or early onset.

-It can occur sporadically or having a genetic background.

What relationship is there between the $A P O E$ gene and dementia or memory loss?

The APOE gene has been cataloged as the main risk factor associated with memory deterioration and/or dementia. There are three main alleles of the gene: E2, E3 and E4. Since two copies are inherited (paternal and maternal), there are 6 possible combinations: E2/ E2, E2/E3, E2/E4, E3/E3, E3/E4 and E4/E4.

The combination influences on the risk for suffering the disease.

\section{E2/E2 \\ Low}

E3/E3 Moderate

E2/E3

\section{E2/E4}

E3/E4

E4/E4

High

The result obtained in the study should be taken with due caution, since it refers

to an increased risk for developing the disease, which means that it has NO diagnostic purposes. 